\title{
Synthesis and Physicochemical Properties of $2-\mathrm{SF}_{5}$ (Aza)Indoles, a New Family of $\mathrm{SF}_{5}$ Heterocycles
}

\author{
Vincent Debrauwer, Ivo Leito, Märt Lõkov, Sofja Tshepelevitsh, Michael Parmentier, \\ Nicolas Blanchard,* and Vincent Bizet*
}

Cite This: ACS Org. Inorg. Au 2021, 1, 43-50

Read Online

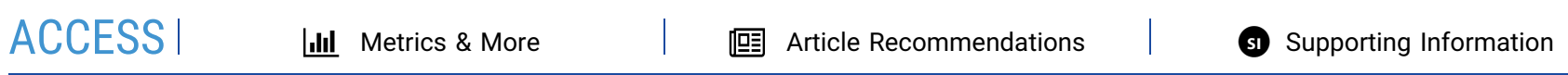

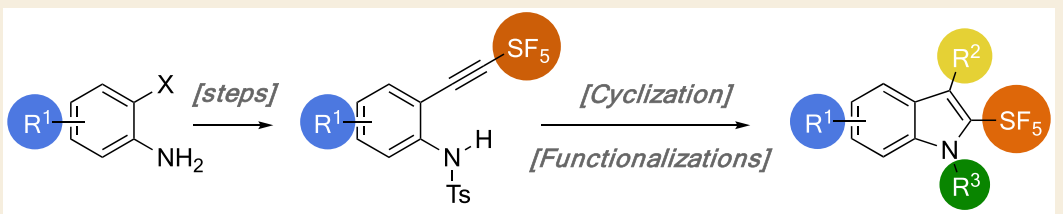

ABSTRACT: Structural diversity in heterocyclic chemistry is key to unlocking new properties and modes of action. In this regard, heterocycles embedding emerging fluorinated substituents hold great promise. Herein is described a strategy to access $2-\mathrm{SF}_{5}{ }^{-}$ (aza)indoles for the first time. The sequence relies on the radical addition of $\mathrm{SF}_{5} \mathrm{Cl}$ to the alkynyl $\pi$-system of 2 -ethynyl anilines followed by a cyclization reaction. A telescoped sequence is proposed, making this strategy very appealing and reproducible on a gram scale. Downstream functionalizations are also demonstrated, allowing an easy diversification of N-and C3-positions. Ames test, $\mathrm{pK}_{\mathrm{a}}, \log P$, and differential scanning calorimetry measurements of several fluorinated 2-Rf-indoles are also disclosed. These studies highlight the strategic advantages that a C2-pentafluorosulfanylated motif impart to a privileged scaffold such as an indole.

KEYWORDS: structural diversity, fluorinated indoles, heterocyclic chemistry, pentafluorosulfanyl

\section{INTRODUCTION}

The incorporation of a fluorinated motif in organic or inorganic molecules influences chemical and physical properties (metabolic stability, bioavailability, $\mathrm{p} K_{\mathrm{a}}$ etc), and this strategy is nowadays widely used in medicinal chemistry. ${ }^{1}$ Among the so-called "emerging" fluorinated groups, the pentafluorosulfanyl group $\left(\mathrm{SF}_{5}\right)^{2,3}$ is of growing interest in heterocyclic synthesis, ${ }^{4-7}$ materials science, ${ }^{8}$ and medicinal chemistry. ${ }^{9}$ The $\mathrm{SF}_{5}$ group has a volume of $55.4 \AA^{3}$, between the $t$ - $\mathrm{Bu}\left(76.9 \AA^{3}\right)$ and $\mathrm{CF}_{3}\left(34.6 \AA^{3}\right)$ groups, and its unique octahedral geometry allows a more selective interaction of $\mathrm{SF}_{5}$ containing molecules with biological receptors. ${ }^{10-12}$ The high lipophilicity of $\mathrm{SF}_{5}$, expressed by the Hansch parameter $(\pi=$ $1.23){ }^{2,13}$ is greater than the ones of $\mathrm{CF}_{3}(0.88)$ or $\mathrm{OCF}_{3}$ (1.04) groups and may confer an enhanced cell membrane permeating ability. The high electronegativity of $\mathrm{SF}_{5}$ expressed by the Hammett constant $\left(\sigma_{\mathrm{p}}=0.68, \sigma_{\mathrm{m}}=0.61\right)^{2,13}$ is also greater than that of $\mathrm{CF}_{3}\left(\sigma_{\mathrm{p}}=0.53, \sigma_{\mathrm{m}}=0.43\right)^{2,13}$ which, in turn, confers high metabolic stability. All of these properties make $\mathrm{SF}_{5}$ an interesting alternative to the $\mathrm{CF}_{3}$ group as a bioisostere, especially in drug development. ${ }^{9,14-16}$

However, synthetic routes to $\mathrm{SF}_{5}$-containing compounds and their structural diversity remain highly challenging. Two general methods are reported for accessing $\mathrm{SF}_{5}$-containing small molecules. The first method is an oxidative fluorination reaction of (hetero)aromatic disulfides, thiols, or, more recently, sulfenyl phthalimides which give access to $\mathrm{ClF}_{4} \mathrm{~S}$ and then $\mathrm{SF}_{5}$-(hetero)aromatic compounds after a final chloride-fluoride exchange step. ${ }^{17-23}$ The second method is a direct introduction of the $\mathrm{SF}_{5}$ group to an alkyne, an alkene, or an $\alpha$-diazo carbonyl thanks to the use of $\mathrm{SF}_{5} \mathrm{Cl}$ gas ${ }^{24}$ under radical conditions to yield $\mathrm{SF}_{5}$-containing compounds. ${ }^{25-28}$ Although the use of commercially available gaseous $\mathrm{SF}_{5} \mathrm{Cl}$ is atom economical and quite straightforward from a practical point of view, recent efforts toward its preparation from sulfur powder, potassium fluoride, and trichloroisocyanuric acid have been disclosed. ${ }^{29,30}$ Recently, $\mathrm{SF}_{6}$ was used as an alternative source of $\mathrm{SF}_{5}{ }^{\bullet}$ in photoredox catalysis, but this method up to now is limited to reactions with styrene derivatives. ${ }^{31-33}$

Indoles are privileged scaffolds in medicinal chemistry, and developing synthetic strategies to modulate their structures and physicochemical properties is of central importance. ${ }^{34-36}$ In this regard, combining indoles and original fluorinated moieties such as the pentafluorosulfanyl group is of interest as it would pave the way to structural and physicochemical studies that could have an impact in medicinal chemistry. Only a handful of $55^{-37-42}$ and $6-\mathrm{SF}_{5}$-indoles ${ }^{43-45}$ are known and were obtained from commercially available $\mathrm{SF}_{5}$-anilines or nitrophenyls (Scheme $1 \mathrm{~B}$ ). However, introducing the $\mathrm{SF}_{5}$

Received: May 19, 2021

Published: July 6, 2021 
Scheme 1. State of the Art for the Introduction of the $\mathrm{SF}_{5}$ Group on Alkyne (A) and on the C5- or C6-Position of Indoles (B) and Proposed Synthetic Strategy for the

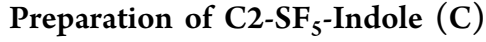

A. Synthesis of $\mathrm{SF}_{5}$-alkynes from terminal alkynes (Dolbier, 2002)

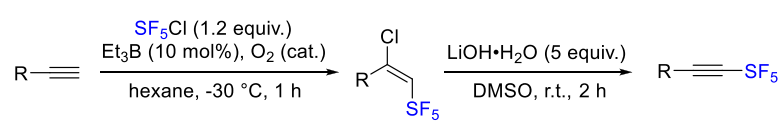

B. Synthetic methods are available for the synthesis of $5-$ or $6-\mathrm{SF}_{5}$-indoles
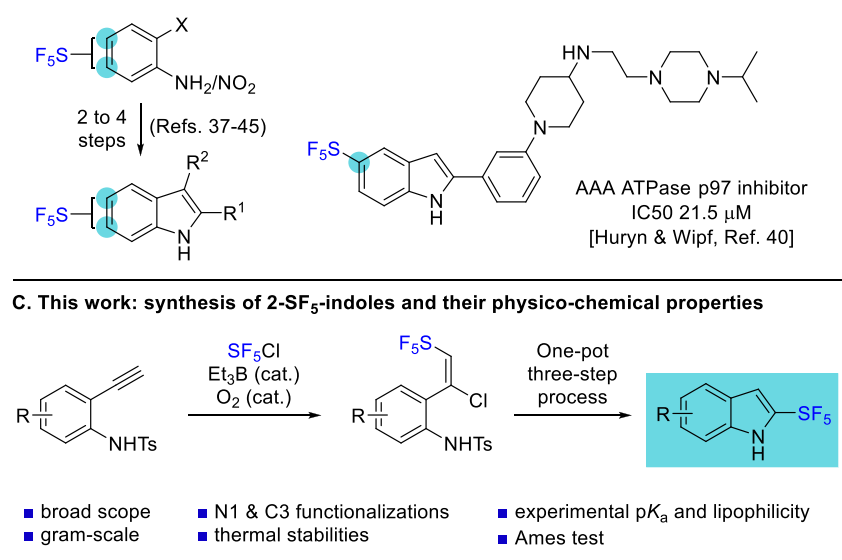

group on other positions of the indole nucleus, and more precisely on the $\mathrm{C} 2$-position, which is as close as possible to the nitrogen atom, is highly challenging and still not reported. Among the different strategies to access $\mathrm{C}_{2}-\mathrm{SF}_{5}$-indoles, the intramolecular 5-endo-dig cyclization ${ }^{46-49}$ of an ortho-alkynylaniline appears to be the most promising (Scheme 1C). Indeed, $\mathrm{SF}_{5}$-substituted alkynes are easily prepared by the reaction between $\mathrm{SF}_{5} \mathrm{Cl}$ and a terminal alkyne under radical conditions followed by basic elimination, as demonstrated by Dolbier (Scheme 1A). ${ }^{25}$ In addition, Tsui reported that $2-\mathrm{CF}_{3}$ indoles could be synthesized via a domino trifluoromethylation/5-endo-dig cyclization of ortho-alkynylanilines. ${ }^{49}$ Herein, we report that this strategic blueprint allows for a general synthesis of $2-\mathrm{SF}_{5}$-indoles from readily available starting materials. Their thermal stabilities, $\mathrm{p} K_{\mathrm{a}}$ values, and lipophilicities were also studied and compared to more classical C2-fluorinated/fluoroalkylated indoles. Finally, evaluation of the mutagenic potential (Ames test) of a selection of $2-\mathrm{SF}_{5}$ indoles was performed.

\section{RESULTS AND DISCUSSION}

$N$-Tosyl-2-ethynylaniline 1 a was selected as a model compound for the screening of chloropentafluorosulfanylation conditions (Scheme 2). ${ }^{50}$ Using catalytic amounts of triethylborane and oxygen, ${ }^{51,52}$ the reaction proceeded smoothly in ethyl acetate or dichloromethane $(0.4 \mathrm{M})$ at -40 to $-20{ }^{\circ} \mathrm{C}$, delivering $2 \mathrm{a}$ in quantitative yield. Gratifyingly, a single regio- and stereoisomer was observed, with the structure of $\mathbf{2 a}$ being unambiguously confirmed by X-ray diffraction (CCDC 2073141). ${ }^{53}$ As reported by Paquin in $2019,{ }^{54}$ several classical organic solvents are compatible with $\mathrm{SF}_{5} \mathrm{Cl}$, and we found that ethyl acetate turned out to be the solvent of choice for the synthesis of $2 a-p$ in terms of conversions and, more importantly, purity. Indeed, in most cases, no further purification of $\mathbf{2}$ is needed. ${ }^{55}$

Electron-donating (4-Me 2b, 4-OMe 2c, and 5-Me 2d) and electron-withdrawing (4-Cl 2e, 4- $\mathrm{CO}_{2} \mathrm{Me} \mathrm{2f,} 4-\mathrm{OCF}_{3} 2 \mathrm{~g}$, 4-
Scheme 2. Scope and Limitations for the Addition of $\mathrm{SF}_{5} \mathrm{Cl}$ to $1^{a}$
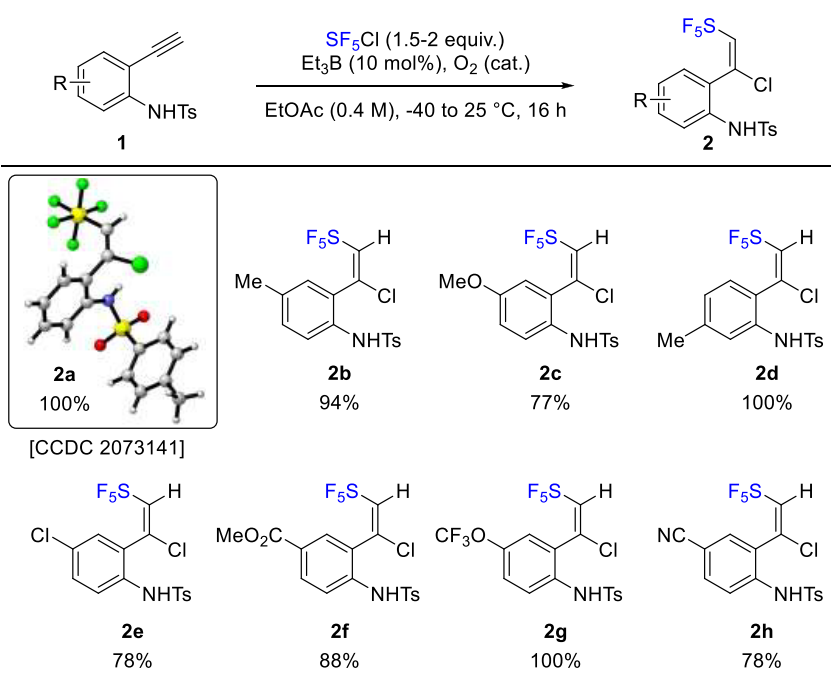
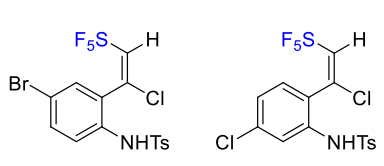

$\mathbf{2 i}$
$100 \%$
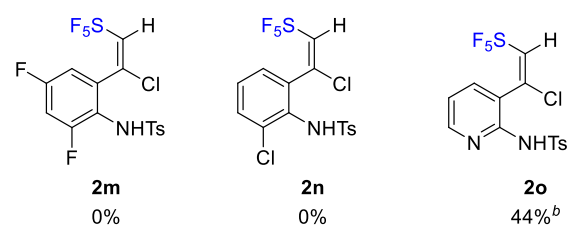

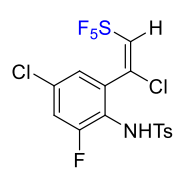

2I

$16 \%$

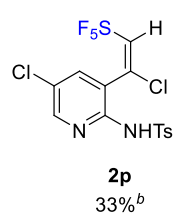

${ }^{a}$ Yields determined by ${ }^{19} \mathrm{~F}$ NMR and ${ }^{1} \mathrm{H}$ NMR using trifluorotoluene as internal standard. ${ }^{b}$ Reaction performed in $\mathrm{CH}_{2} \mathrm{Cl}_{2}$ instead of EtOAc.

$\mathrm{CN} 2 \mathbf{h}, 4-\mathrm{Br} 2 \mathbf{i}, 5-\mathrm{Cl} 2 \mathbf{j}$, and 5-F $2 \mathbf{k}$ ) substituents on the aromatic ring are well-tolerated and give high NMR yields (77-100\%). Noteworthy, when the conversion is high, the crude product $\mathbf{2}$ is very clean and can be used for the next step without further purification. In a few cases, we noticed that with 6-F 2l,m and 6-Cl $2 \mathrm{n}$ aniline derivatives, very low conversion or no reaction was observed. Much to our delight, 2 -aminopyridine derivatives are tolerated, and $\mathrm{SF}_{5}$ adducts 2o,p were obtained in 44 and 33\% yields, respectively.

For the subsequent step, we first tested basic conditions described by Dolbier for the dehydrochlorination reaction ( $\mathrm{LiOH}$ in DMSO). ${ }^{25}$ After $16 \mathrm{~h}$ at room temperature, we were pleased to observe full conversion of $2 \mathrm{a}$ to the expected $\mathrm{SF}_{5}$ alkyne 3a, along with $N$-Ts-2-SF - -indole 4 a in a 50:50 ratio (as measured by ${ }^{19} \mathrm{~F}$ NMR, Scheme 3 ). Extended reaction times, up to $84 \mathrm{~h}$, afforded a 47:53 mixture of $\mathrm{N}$-Ts-2-SF $\mathrm{F}_{5}$-indole $4 \mathrm{a}$ and $2-\mathrm{SF}_{5}$-indole $\mathbf{5 a}$ (arising from the deprotection of $4 \mathrm{a}$ under basic conditions). Structures of 4a (CCDC 2073143) and 5a (CCDC 2073142) were unambiguously confirmed by X-ray diffraction. ${ }^{56}$ After careful optimization, it was found that full conversion of $2 \mathrm{a}$ into $5 \mathrm{a}$ was obtained after $40 \mathrm{~h}$ at $40{ }^{\circ} \mathrm{C}$. This one-pot three-step sequence (dehydrochlorination, 5-endo-dig cyclization, and deprotection of the tosyl moiety) is general and proceeds smoothly with all substrates $2 \mathbf{a}-\mathbf{p}$ independently of the substitution. 
Scheme 3. Scope and Limitations for the Synthesis of 2-SF Indoles $5^{a}$

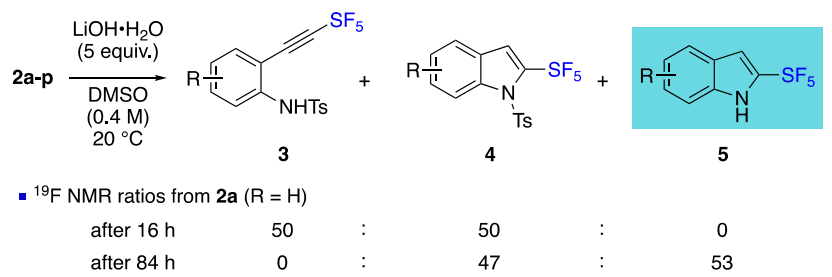

- Optimized conditions for the scope : $\mathrm{LiOH} \cdot \mathrm{H}_{2} \mathrm{O}$ (5 equiv.), DMSO $(0.4 \mathrm{M}), 40^{\circ} \mathrm{C}, 40 \mathrm{~h}$

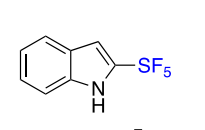

5 a

$66 \%$ over 2 steps ( $1.8 \mathrm{~g}$ scale)<smiles>COc1ccc2[nH]c(C(F)(F)F)cc2c1</smiles>

$5 \mathrm{c}$

$100 \%(68 \%)$<smiles>CC(=O)c1ccc2[nH]c(C(F)(F)F)cc2c1</smiles>

$5 \mathbf{f}$

$71 \%(41 \%)$<smiles>Fc1cc2cc(Br)ccc2[nH]1</smiles>

$5 \mathbf{i}$

$90 \%(58 \%)$<smiles>Fc1cc(Cl)cc2cc(S(F)(F)(F)(F)F)[nH]c12</smiles>

$100 \%(49 \%)$

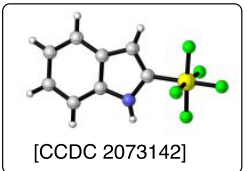<smiles>Cc1ccc2cc(C(F)(F)F)[nH]c2c1</smiles>

$5 d$<smiles>FC(F)(F)Oc1ccc2[nH]c(C(F)(F)F)cc2c1</smiles>

$5 \mathrm{~g}$

$68 \%(38 \%)$
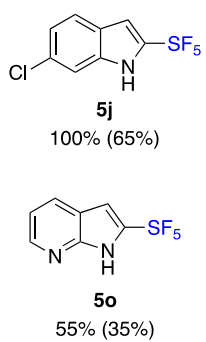

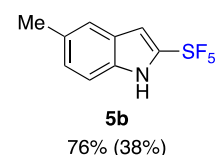

$76 \%(38 \%)$

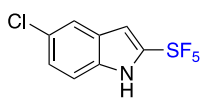

5 e $90 \%(53 \%)$

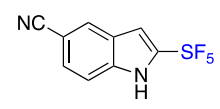
$90 \%(40 \%)$
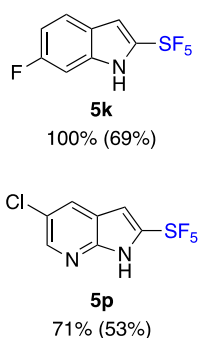

${ }^{a}$ NMR yields determined by ${ }^{19} \mathrm{~F}$ NMR and ${ }^{1} \mathrm{H}$ NMR using trifluorotoluene as internal standard. Isolated yields in brackets after purification on $\mathrm{SiO}_{2}$.

Good to excellent NMR yields ranging from 55\% to quantitative are obtained. Noteworthy, functional groups such as ester $\mathbf{5 f}$, nitrile $\mathbf{5 h}$, halides $\mathbf{5 e}-\mathbf{5 i}, \mathbf{j}$, or even the more exotic $\mathrm{OCF}_{3} \mathbf{5 g}$ are well-tolerated. It should be noted that isolated yields of $2-\mathrm{SF}_{5}$-indoles 5 are $34 \pm 16 \%$ lower (after chromatography on silica gel) than NMR yields. Unfortunately, all of the purification media that were screened, such as deactivated silica gel, demetalated silica gel, ${ }^{57} \mathrm{C}-18$ reversedphase silica, Florisil, or alumina did not improve yields further. However, $60-70 \%$ overall yields are still highly relevant considering that this is a formal three-step sequence. In addition, the reaction is easily scalable up to $1.8 \mathrm{~g}(4 \mathrm{mmol})$ in reproducible $66 \%$ isolated yield.

While the synthesis of $\mathrm{N}$-unprotected $2-\mathrm{SF}_{5}$-indoles 5 is of interest, keeping the $N$-tosyl protecting group would also be an asset. After an extensive screening of base, it was found that lithium hexamethyldisilazane (LiHMDS) led to a smooth dehydrochlorination reaction at $-78{ }^{\circ} \mathrm{C}$ for $1 \mathrm{~h}$ (Scheme 4). $\mathrm{SF}_{5}$-Alkynes 3 were formed in $77-100 \%$ yield, with an excellent functional group tolerance. In addition, the reaction was very clean, and no purification was needed. Next, for the cyclization step, it was found that $\mathrm{K}_{3} \mathrm{PO}_{4}$ was able to convert
Scheme 4. Synthesis $\mathrm{SF}_{5}$-Alkynes $3^{a}$

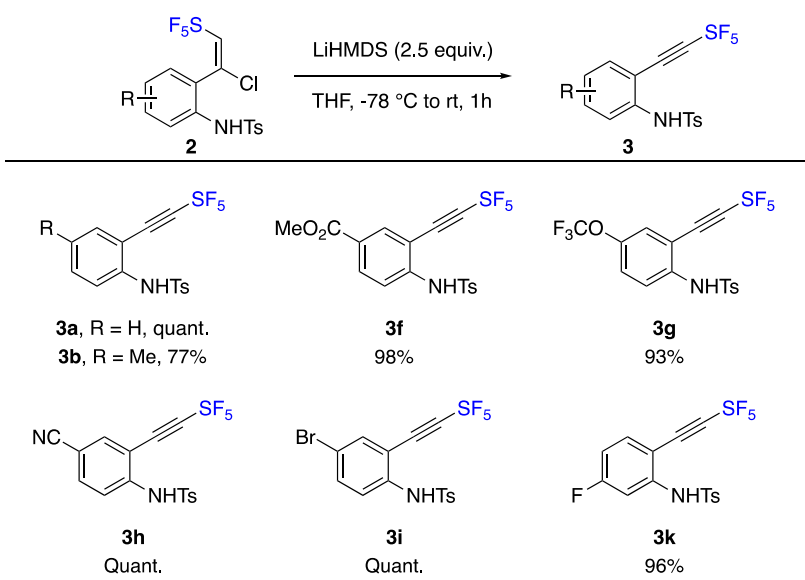

${ }^{a}$ Isolated yields after extraction; no purification needed.

$\mathrm{SF}_{5}$-alkynes 3 into the desired $\mathrm{N}$-Ts-2-SF -indoles 4 in acetonitrile at $40{ }^{\circ} \mathrm{C}$ for $12 \mathrm{~h}$ alongside the deprotected indole 5 (Scheme 5). As expected from an electronic point of view, electron-neutral or electron-donating substituents as in $\mathbf{3 a}, \mathbf{b}$ gave high selectivity for the corresponding $\mathrm{N}-\mathrm{Ts}-2-\mathrm{SF}_{5}$-indoles 4a,b.

Scheme 5. Synthesis of N-Ts-2-SF 5 -Indoles $4^{a}$

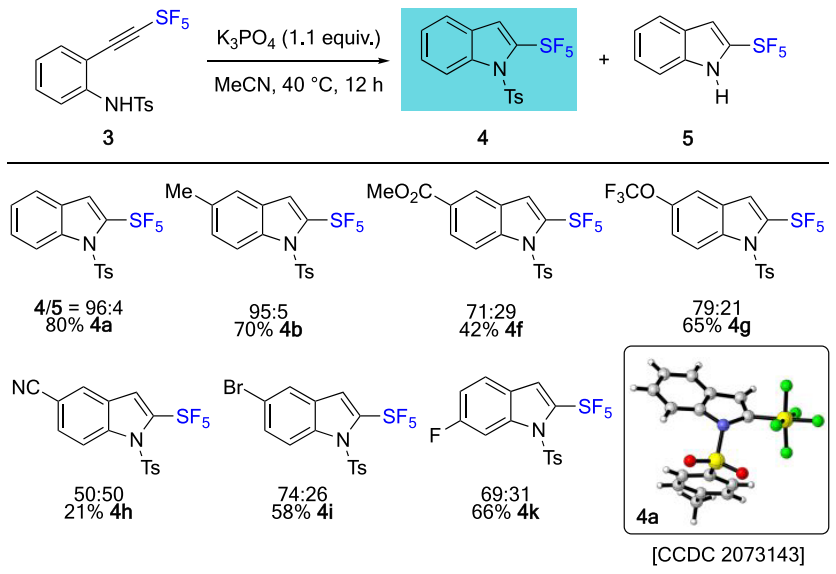

${ }^{a}$ Isolated yields after purification on $\mathrm{SiO}_{2}$. Ratio of $4 / 5$ determined by ${ }^{19} \mathrm{~F}$ NMR using trifluorotoluene as an internal standard.

In contrast, with electron-withdrawing substituents, a nonnegligible amount of $2-\mathrm{SF}_{5}$-indoles $\mathbf{5 f}-\mathbf{i}, \mathbf{k}\left(\mathrm{R}=\mathrm{Br}, \mathrm{F}, \mathrm{OCF}_{3}\right.$, $\mathrm{CO}_{2} \mathrm{Me}, \mathrm{CN}$ ) was observed ranging from $30 \%$ with $\mathrm{R}=$ $\left.\mathrm{CO}_{2} \mathrm{Me} \mathrm{OCF}_{3}, \mathrm{Br}, \mathrm{F}\right)$ to $50 \%$ with $\mathrm{R}=\mathrm{CN}$. Quite interestingly, isolated yields of $\mathrm{N}$-Ts-2-SF $\mathrm{S}_{5}$-indoles 4 are much closer to NMR yields, which indicates that $\mathrm{N}$-substituted $2-\mathrm{SF}_{5}$-indoles possess improved stability toward purification. This was further confirmed by the independent preparation of $\mathrm{N}$-Bn-2-SF ${ }_{5}$-indole 7 and $\mathrm{N}$-Me-2-SF - -indole 8 via the interception of the intermediate 6 by the corresponding electrophiles (Scheme 6A). Clean reactions and excellent yields for five steps were obtained, in line with the NMR yields (92\% for 7 and $73 \%$ for 8 , a mean deviation of $7 \pm 2 \%$ from the isolated yields).

C3-Functionalizations of $2-\mathrm{SF}_{5}$-indoles 5 were next investigated (Scheme 6B,C). We first focused on the innate C3nucleophilicity of $\mathbf{5 a}$ in halogenation reactions. Double 
Scheme 6. Downstream Functionalizations of 2-SF Indoles $^{a}$

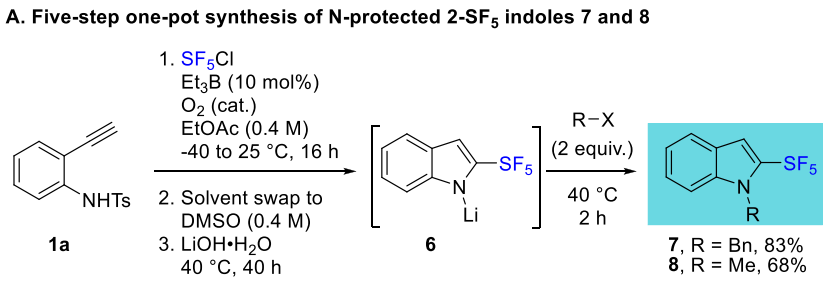

B. C3-Halogenation reactions of $2-\mathrm{SF}_{5}$-indole $5 \mathrm{a}$

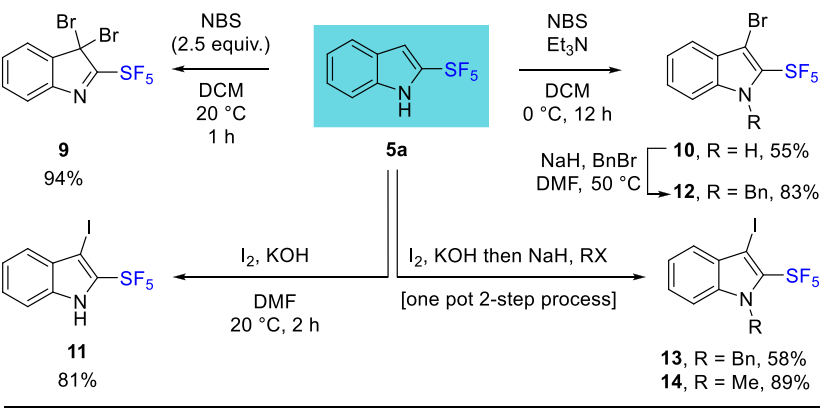

C. C-C Bond formation at the $\mathrm{C} 3$-position of 2-SF ${ }_{5}$-indoles

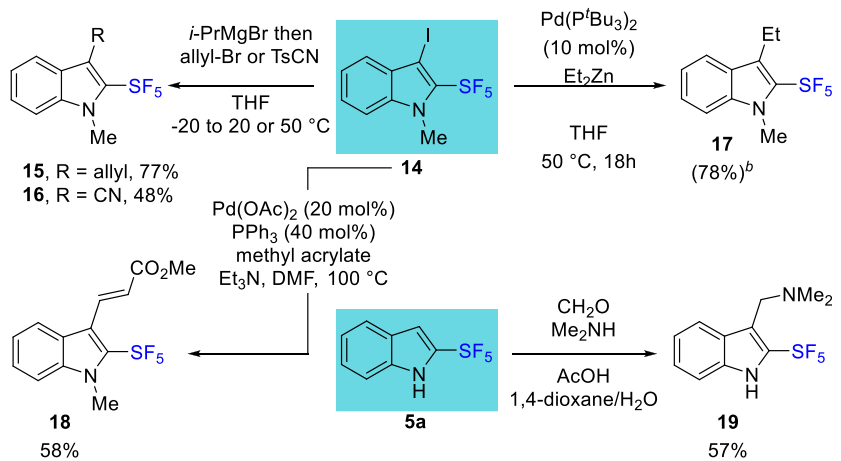

${ }^{a}$ NMR yield determined by ${ }^{19} \mathrm{~F}$ NMR using trifluorotoluene as an internal standard. ${ }^{b}$ Obtained as an inseparable mixture with indole 8.

bromination reaction ${ }^{58}$ with an excess of $\mathrm{N}$-bromosuccinimide (NBS) is very efficient and yielded 9a in 94\% yield.
Monobromination is also possible using a slight excess (1.1 equiv) of NBS in the presence of triethylamine. ${ }^{59}$ The reaction proceeded quantitatively by NMR and $\mathbf{1 0}$ was isolated in 55\% yield. Incorporation of a C3-iodine atom is also possible using molecular iodine in the presence of potassium hydroxide, ${ }^{60}$ delivering 11 in $81 \%$ yield. The iodination step can then be combined in a one-pot process with N-benzylation (13, 58\%) or N-methylation $(14,89 \%)$. Finally, $\mathrm{C}-\mathrm{C}$ bond formations were investigated (Scheme $6 \mathrm{C}$ ). Iodine-magnesium exchange of $\mathbf{1 4}$ followed by trapping with an electrophile such as allyl bromide or tosyl cyanide delivered 15 (77\%) and 16 (48\%), respectively. ${ }^{61}$ Negishi cross-coupling with diethylzinc ${ }^{62}$ proved to be efficient with the formation of 17 in $78 \%$ NMR yield (along with the reduced indole 8 as an inseparable mixture). Heck cross-coupling ${ }^{63,64}$ with methyl acrylate is also productive, yielding 18 in $58 \%$ yield as a single $E$-stereoisomer. Finally, we evaluated the reactivity of the $2-\mathrm{SF}_{5}$-indole 5 a toward Eschenmoser salt for the synthesis of 19 (57\%), the 2$\mathrm{SF}_{5}$ analogue of the naturally occurring indole alkaloid gramine. $^{65}$

Having designed a synthetic strategy toward $2-\mathrm{SF}_{5}$-indoles and explored a selection of downstream functionalizations, we turned our attention to the investigation of their physicochemical properties and how they compare with differently C2substituted indoles. Six indoles were selected: the 2-SF indoles $\mathbf{5 a}$ and $\mathbf{8}$ alongside four $\mathrm{C} 2$-substituted indoles, $2-\mathrm{H}$ (20), 2-Me (21), 2-F (22), and 2- $\mathrm{CF}_{3}(23)$.

We started with differential scanning calorimetry (DSC) $)^{66-69}$ analysis to gain information about the thermal tolerance threshold of our process and the thermal stability of

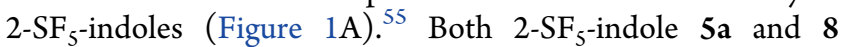
induce a strong release of energy (exothermic) when the threshold of thermal stability is reached, with enthalpies of $-1180 \mathrm{~kJ} / \mathrm{kg}$ with an onset above $165{ }^{\circ} \mathrm{C}$ for $5 \mathrm{a}$ and -1324 $\mathrm{kJ} / \mathrm{kg}$ starting above $310{ }^{\circ} \mathrm{C}$ for 8 .

This highly exothermic event is characteristic of a violent decomposition. However, this threshold appears at relatively high temperatures $\left(>165{ }^{\circ} \mathrm{C}\right.$ for $5 \mathrm{a}, 310{ }^{\circ} \mathrm{C}$ for 8) and therefore much higher than the maximum temperatures used for the synthesis of $2-\mathrm{SF}_{5}$-indoles (up to $40{ }^{\circ} \mathrm{C}$ ) or their functionalization (up to $100{ }^{\circ} \mathrm{C}$ ). This means that the
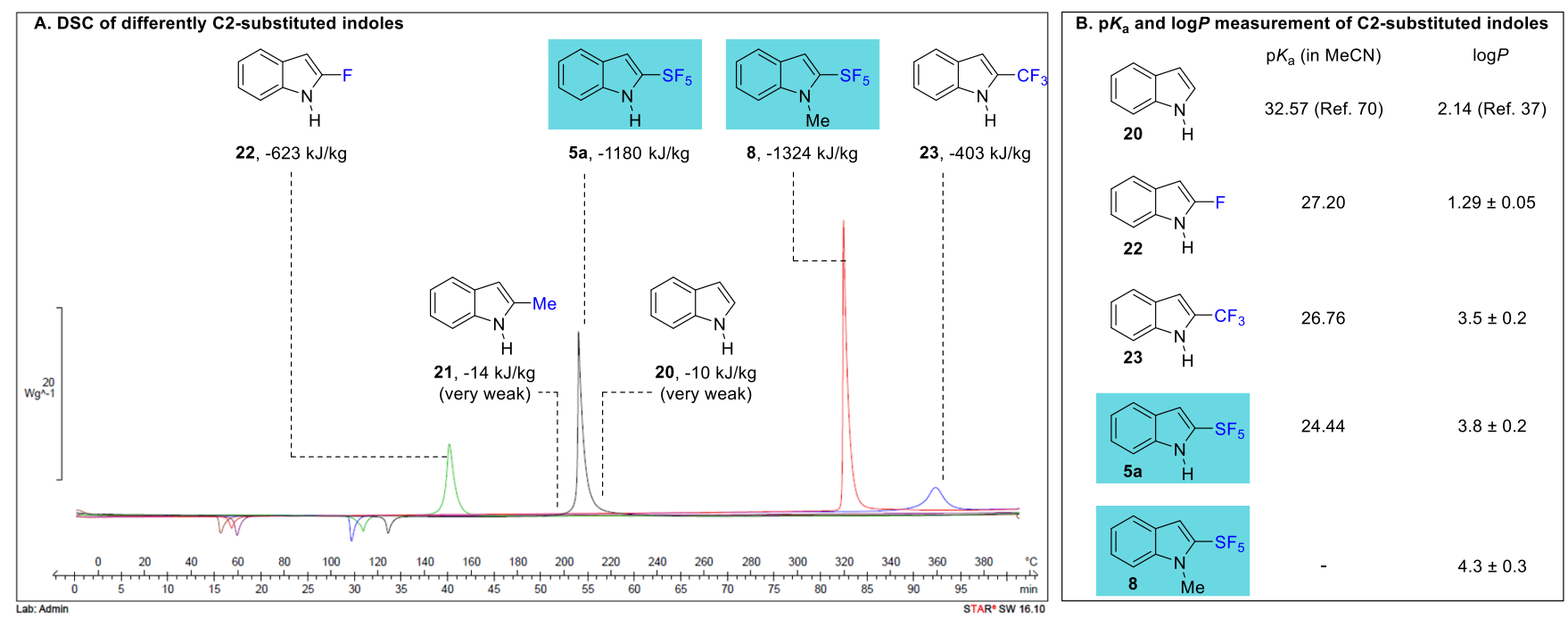

Figure 1. Differential scanning calorimetry (A) and $\mathrm{p} K_{\mathrm{a}}$ and $\log P(\mathrm{~B})$ of $\mathrm{C} 2$-substituted indoles. 
synthetic methods devised in Schemes 2-6 are safe with a fairly large safety margin gap $\left(>120^{\circ} \mathrm{C}\right)$ between the reaction processes and the decomposition onsets. As expected, the protection of $2-\mathrm{SF}_{5}$-indole $\mathbf{5 a}$ by a methyl group (8) significantly increases its thermal stability. Among the fluorinated indole analogues, $2-\mathrm{CF}_{3}$ indole $\mathbf{2 3}$ is the most stable heterocycle with an exothermic degradation above 325 ${ }^{\circ} \mathrm{C}(-403 \mathrm{~kJ} / \mathrm{kg})$, whereas $2-\mathrm{F}$ indole 22 degrades above 120 ${ }^{\circ} \mathrm{C}(-623 \mathrm{~kJ} / \mathrm{kg})$. It is important to note that, in comparison, the temperatures and degradation energies of 2-Me indole 21 (low exotherm above $165{ }^{\circ} \mathrm{C}$, enthalpy of $-14 \mathrm{~kJ} / \mathrm{kg}$ ) and indole 20 (low exotherm above $190{ }^{\circ} \mathrm{C}$, enthalpy of $-10 \mathrm{~kJ} /$ $\mathrm{kg}$ ) are negligible.

Incorporation of a fluorine atom or a fluorinated group has a tremendous impact on physicochemical properties of molecules and nearby functional groups. In the specific case of the pentafluorosulfanyl moiety, physicochemical data are scarce ${ }^{2-6}$ and experimental measurements of the acidity $\left(\mathrm{pK}_{\mathrm{a}}\right)^{70}$ and lipophilicity $(\log P)^{71,72}$ imparted by the pentafluorosulfanyl moiety would be useful data for medicinal chemistry programs. We thus turned our attention to a subset of indoles substituted at $\mathrm{C}-2$ by $\mathrm{H}(\mathbf{2 0}), \mathrm{F}(\mathbf{2 2}), \mathrm{CF}_{3}(\mathbf{2 3})$, or $\mathrm{SF}_{5}(\mathbf{5 a} / 8)$, and the results are summarized in Figure $1 \mathrm{~B}$. Values of $\mathrm{p} K_{\mathrm{a}}$ were measured in acetonitrile by spectrophotometric titration. ${ }^{55}$ The $\mathrm{p} K_{\mathrm{a}}$ of indole $20(32.57)^{70}$ decreases dramatically by 5.4 units upon fluorine and fluorine-containing substitution at $\mathrm{C} 2$, resulting in $\mathrm{pK}_{\mathrm{a}} 27.20$ for 22. Swapping C2-F for a C2-CF substituent only slightly impacted the $\mathrm{p} K_{\mathrm{a}}$ by 0.44 units $\left(\mathrm{p} K_{\mathrm{a}}\right.$ of 23: 26.76). On the other hand, a pronounced drop in $\mathrm{p} K_{\mathrm{a}}$ was measured for 5 a possessing a $\mathrm{C}_{2}-\mathrm{SF}_{5}$ motif; with a $\mathrm{p} K_{\mathrm{a}}$ of 24.44, it stands 2.32 units lower than the $\mathrm{p} K_{\mathrm{a}}$ of 23 and is comparable to the $\mathrm{p} K_{\mathrm{a}}$ of 2-nitroindole (23.64). ${ }^{70}$

Fine modulation of lipophilicity is central to drug development, ${ }^{73-75}$ and fluorine-containing substituents play an important role in this regard, whether in the aromatic ${ }^{76}$ or aliphatic series. ${ }^{77-79}$ As a consequence, assessing the impact of the pentafluorosulfanyl motif at the C2-position of indoles on $\log P$ was of interest. The lipophilicities of the five indole derivatives were obtained by combining experimental and computational data. ${ }^{55}$ The average $\log P$ values are given in Figure 1B. Replacement of the C2-hydrogen atom of indole $\mathbf{2 0}$ by a fluorine atom (22) decreases the lipophilic character by 0.85 unit (from 2.14 to 1.29 ). Although lipophilicity classically increases upon $\mathrm{H}-\mathrm{F}$ swap in the aromatic series, this drop in $\log P$ between $\mathbf{2 0}$ and $\mathbf{2 2}$ can be rationalized by the increased polarization of the $\mathrm{N}-\mathrm{H}$ bond, leading to the increased hydrogen bond donating ability of $\mathbf{2 2}$ (favoring hydrophilicity) balanced by a small increase in hydrophobic surface area. ${ }^{76,80}$ On the other hand, the latter parameter dramatically increases in the case of $2-\mathrm{CF}_{3}$-indole 23 , overcompensating the increased hydrogen bonding ability. An increase of $\log P$ to $3.5 \pm 0.2$ was measured for 23. Replacing $2-\mathrm{CF}_{3}$ with $2-\mathrm{SF}_{5}$ substituent as in compound 5a further increases $\log P$ by roughly 0.3 units, to $3.8 \pm 0.2$. Finally, $\mathrm{N}$-methylation of 5 a logically led to an increased $\log P$ of $4.3 \pm 0.3$. Overall, these results allow the assessment of the impact of the pentafluorosulfanyl group compared to a fluorine atom or a trifluoromethyl group in the C2-position of indoles. A pronounced drop in $\mathrm{p} K_{\mathrm{a}}$ and a simultaneous increase in $\log P$ are unambiguously demonstrated, thereby modulating physicochemical properties of this relevant heterocycle in a unique fashion.

Finally, as indole is a privileged scaffold in drug discovery, we thought that the mutagenic character of the newly synthesized compounds $5 \mathbf{5}$ and $\mathbf{8}$ will be important to be determined and valuable information to be provided to the community. In silico assessment is typically done in the first place to estimate the mutagenic potential of a compound against databases. Indole is considered to be nonmutagenic, and therefore, there is no mutagenicity concern emerging from the indole moiety. However, uncovered fragment $-\mathrm{SF}_{5}$ was detected in the used systems (Derek, Sarah Nexus, and Case Ultra). ${ }^{55}$ Hence, due to incomplete coverage, it was recommended to perform further tests to evaluate potential mutagenic activity of the $\mathrm{SF}_{5}$ moiety. We thus performed the Ames test which is a classical biological test to determine the mutagenic potential of a chemical compound. ${ }^{55}$ Since cancers are often linked to damage to DNA, this rapid, reliable, and inexpensive test is used to estimate the carcinogenic and genetic activity at the nucleotide level, based on different histidine-requiring bacterial strains of Salmonella typhimurium carrying mutations in the genes in the absence and presence of a liver-metabolizing system. ${ }^{81,82}$ Over the years, a large database has been accumulated with this assay, confirming its ability to detect genetically active compounds of most chemical classes with around $80-90 \%$ sensitivity and specificity. The 2$\mathrm{SF}_{5}$-indoles $5 \mathrm{a}$ and $\mathbf{8}$ have been tested, and no mutagenic evidence was observed over the different bacterial strains tested, which means that they can potentially be used for further development in drug discovery.

\section{CONCLUSION}

In conclusion, we developed an efficient synthesis of $2-\mathrm{SF}_{5}$ indoles and azaindoles from 2-ethynylaniline derivatives in a two-step telescoped procedure. This sequence consists of four formal synthetic steps: radical addition of $\mathrm{SF}_{5} \mathrm{Cl}$ followed by dehydrochlorination, 5-endo-dig cyclization and deprotection of the tosyl fragment in basic conditions. We then decomposed the full sequence into a stepwise synthesis allowing to keep the $\mathrm{N}$-protecting group on the $2-\mathrm{SF}_{5}$-indole. A selection of downstream functionalizations was demonstrated, including $\mathrm{N}$-alkylation and benzylation, C3-halogenation, alkylation, allylation, cyanation, and alkenylation. Carcinogenic potential (Ames test) and relevant physicochemical properties (such as thermal stability (DSC), acidity $\left(\mathrm{pK}_{\mathrm{a}}\right)$, and lipophilicity $(\log P)$ were measured in order to highlight the strategic advantages that a C2-pentafluorosulfanylated motif could impart on the indole nucleus.

\section{ASSOCIATED CONTENT}

\section{Supporting Information}

The Supporting Information is available free of charge at https://pubs.acs.org/doi/10.1021/acsorginorgau.1c00010.

Detailed procedures and characterization of all products; copies of ${ }^{1} \mathrm{H},{ }^{13} \mathrm{C}$, and ${ }^{19} \mathrm{~F}$ NMR (PDF)

\section{Accession Codes}

CCDC 2073141-2073143 contain the supplementary crystallographic data for this paper. These data can be obtained free of charge via www.ccdc.cam.ac.uk/data_request/cif, or by emailing data_request@ccdc.cam.ac.uk, or by contacting The Cambridge Crystallographic Data Centre, 12 Union Road, Cambridge CB2 1EZ, UK; fax: +44 1223336033. 


\section{AUTHOR INFORMATION}

\section{Corresponding Authors}

Nicolas Blanchard - Université de Haute-Alsace, Université de Strasbourg, CNRS, LIMA, UMR 7042, 68000 Mulhouse, France; (1) orcid.org/0000-0002-3097-0548; Email: n.blanchard@unistra.fr

Vincent Bizet - Université de Haute-Alsace, Université de Strasbourg, CNRS, LIMA, UMR 7042, 68000 Mulhouse, France; (1) orcid.org/0000-0002-0870-1747; Email: vbizet@unistra.fr

\section{Authors}

Vincent Debrauwer - Université de Haute-Alsace, Université de Strasbourg, CNRS, LIMA, UMR 7042, 68000 Mulhouse, France

Ivo Leito - Institute of Chemistry, University of Tartu, Tartu 50411, Estonia; (1) orcid.org/0000-0002-3000-4964

Märt Lõkov - Institute of Chemistry, University of Tartu, Tartu 50411, Estonia; (1) orcid.org/0000-0003-4484-0864

Sofja Tshepelevitsh - Institute of Chemistry, University of Tartu, Tartu 50411, Estonia

Michael Parmentier - Chemical and Analytical Development, Novartis Pharma AG, CH-4056 Basel, Switzerland; (1) orcid.org/0000-0002-1732-9641

Complete contact information is available at:

https://pubs.acs.org/10.1021/acsorginorgau.1c00010

Notes

The authors declare no competing financial interest.

\section{ACKNOWLEDGMENTS}

This work was supported by the French National Research Agency (Grant No. ANR-PRC-17-CE07-0008), Université de Haute-Alsace, Université de Strasbourg, CNRS, Région GrandEst, and Foundation for Frontier Research in Chemistry (ICFRC). The authors thank Pascale Hoehn (safety lab, DSC) and Susanne Glowienke and Erika Udovic (preclinical safety, Ames test, in silico) from Novartis. Work at Tartu was supported by the Estonian Research Council grant (PRG690), by EU through the European Regional Development Fund under project TK141 "Advanced materials and high-technology devices for energy recuperation systems" (20142020.4.01.15-0011) and was carried out using the instrumentation at the Estonian Center of Analytical Chemistry (www. akki.ee). The authors thank Dr. F. Leroux, Dr. G. Hanquet, Dr. A. Panossian, Dr. C. Meyer, and Dr. S. Lakhdar for fruitful discussions. This article is dedicated to the memory of Francis Marty, Emeritus Professor at the University of Burgundy, France.

\section{REFERENCES}

(1) Wang, J.; Sánchez-Roselló, M.; Aceña, J. L.; del Pozo, C.; Sorochinsky, A. E.; Fustero, S.; Soloshonok, V. A.; Liu, H. Fluorine in Pharmaceutical Industry: Fluorine-Containing Drugs Introduced to the Market in the Last Decade (2001-2011). Chem. Rev. 2014, 114, 2432-2506.

(2) Savoie, P. R.; Welch, J. T. Preparation and Utility of Organic Pentafluorosulfanyl-Containing Compounds. Chem. Rev. 2015, 115, $1130-1190$.

(3) von Hahmann, C. N.; Savoie, P. R.; Welch, J. T. Reactions of Organic Pentafluorosulfanyl-containing Compounds. Curr. Org. Chem. 2015, 19, 1592-1618.
(4) Kanishchev, O. S.; Dolbier, W. R. Chapter One - $\mathrm{SF}_{5}$-Substituted Aromatic Heterocycles. In Advances in Heterocyclic Chemistry, Scriven, E. F. V., Ramsden, C. A., Eds.; Academic Press, 2016; Vol. 120, pp 142

(5) Das, P.; Tokunaga, E.; Shibata, N. Recent Advancements in the Synthesis of Pentafluorosulfanyl $\left(\mathrm{SF}_{5}\right)$-Containing Heteroaromatic Compounds. Tetrahedron Lett. 2017, 58, 4803-4815.

(6) Cui, B.; Shibata, N. The Story of $\mathrm{SF}_{5}$-Substituted Pyridines. Phosphorus, Sulfur Silicon Relat. Elem. 2019, 194, 658-663.

(7) Beier, P. Pentafluorosulfanylation of Aromatics and Heteroaromatics. In Emerging Fluorinated Motifs: Synthesis, Properties and Applications; Cahard, D., Ma, J.-A., Eds.: Wiley-VCH: Weinheim, Germany, 2020; Vol 2, pp 551-570.

(8) Chan, J. M. W. Pentafluorosulfanyl Group: an Emerging Tool in Optoelectronic Materials. J. Mater. Chem. C 2019, 7, 12822-12834.

(9) Sowaileh, M. F.; Hazlitt, R. A.; Colby, D. A. Application of the Pentafluorosulfanyl Group as a Bioisosteric Replacement. ChemMedChem 2017, 12, 1481-1490.

(10) Altomonte, S.; Zanda, M. Synthetic Chemistry and Biological Activity of Pentafluorosulphanyl $\left(\mathrm{SF}_{5}\right)$ Organic Molecules. J. Fluorine Chem. 2012, 143, 57-93.

(11) Meanwell, N. A. Fluorine and Fluorinated Motifs in the Design and Application of Bioisosteres for Drug Design. J. Med. Chem. 2018, $61,5822-5880$.

(12) Savoie, P. R.; von Hahmann, C. N.; Penger, A.; Wei, Z.; Welch, J. T. The Control of Stereochemistry by the Pentafluorosulfanyl Group. Org. Biomol. Chem. 2018, 16, 3151-3159.

(13) Sheppard, W. A. The Electrical Effect of the Sulfur Pentafluoride Group. J. Am. Chem. Soc. 1962, 84, 3072-3076.

(14) Welch, J. T.; Lim, D. S. The Synthesis and Biological Activity of Pentafluorosulfanyl Analogs of Fluoxetine, Fenfluramine, and Norfenfluramine. Bioorg. Med. Chem. 2007, 15, 6659-6666.

(15) Lim, D. S.; Choi, J. S.; Pak, C. S.; Welch, J. T. Synthesis and Herbicidal Activity of a Pentafluorosulfanyl Analog of Trifluralin. J. Pestic. Sci. 2007, 32, 255-259.

(16) Gujjar, R.; El Mazouni, F.; White, K. L.; White, J.; Creason, S.; Shackleford, D. M.; Deng, X.; Charman, W. N.; Bathurst, I.; Burrows, J.; Floyd, D. M.; Matthews, D.; Buckner, F. S.; Charman, S. A.; Phillips, M. A.; Rathod, P. K. Lead Optimization of Aryl and Aralkyl Amine-Based Triazolopyrimidine Inhibitors of Plasmodium falciparum Dihydroorotate Dehydrogenase with Antimalarial Activity in Mice. J. Med. Chem. 2011, 54, 3935-3949.

(17) Umemoto, T.; Garrick, L. M.; Saito, N. Discovery of Practical Production Processes for Arylsulfur Pentafluorides and Their Higher Homologues, Bis- and Tris(sulfur pentafluorides): Beginning of a New Era of "Super-Trifluoromethyl" Arene Chemistry and its Industry. Beilstein J. Org. Chem. 2012, 8, 461-471.

(18) Kosobokov, M.; Cui, B.; Balia, A.; Matsuzaki, K.; Tokunaga, E.; Saito, N.; Shibata, N. Importance of a Fluorine Substituent for the Preparation of meta- and para-Pentafluoro- $\lambda^{6}$-sulfanyl-Substituted Pyridines. Angew. Chem., Int. Ed. 2016, 55, 10781-10785.

(19) Cui, B.; Jia, S.; Tokunaga, E.; Saito, N.; Shibata, N. SilverInduced Self-Immolative Cl-F Exchange Fluorination of Arylsulfur Chlorotetrafluorides: Synthesis of Arylsulfur Pentafluorides. Chem. Commun. 2017, 53, 12738-12741.

(20) Cui, B.; Kosobokov, M.; Matsuzaki, K.; Tokunaga, E.; Shibata, N. $\mathrm{IF}_{5}$ Affects the Final Stage of the Cl-F Exchange Fluorination in the Synthesis of Pentafluoro- $\lambda^{6}$-Sulfanyl-Pyridines, Pyrimidines and Benzenes with Electron-Withdrawing Substituents. Chem. Commun. 2017, 53, 5997-6000.

(21) Pitts, C. R.; Bornemann, D.; Liebing, P.; Santschi, N.; Togni, A. Making the $\mathrm{SF}_{5}$ Group More Accessible: A Gas-Reagent-Free Approach to Aryl Tetrafluoro- $\lambda^{6}$-sulfanyl Chlorides. Angew. Chem. Int. Ed. 2019, 58, 1950-1954.

(22) Wang, L.; Cornella, J. A Unified Strategy for Arylsulfur(VI) Fluorides from Aryl Halides: Access to $\mathrm{Ar}-\mathrm{SOF}_{3}$ Compounds. Angew. Chem., Int. Ed. 2020, 59, 23510-23515.

(23) Tanagawa, K.; Zhao, Z.; Saito, N.; Shibata, N. AgBF 4 -mediated Chlorine-Fluorine Exchange Fluorination for the Synthesis of 
Pentafluorosulfanyl (Hetero)arenes. Bull. Chem. Soc. Jpn. 2021, 94, 1682.

(24) Burton, D. J.; Wang, Y.; Bizet, V.; Cahard, D. Pentafluorosulfanyl Chloride. e-EROS Encyclopedia of Reagents for Organic Synthesis; Wiley, 2020.

(25) Ait-Mohand, S.; Dolbier, W. R. New and Convenient Method for Incorporation of Pentafluorosulfanyl $\left(\mathrm{SF}_{5}\right)$ Substituents Into Aliphatic Organic Compounds. Org. Lett. 2002, 4, 3013-3015.

(26) Dolbier, W. R., Jr; Aït-Mohand, S.; Schertz, T. D.; Sergeeva, T. A.; Cradlebaugh, J. A.; Mitani, A.; Gard, G. L.; Winter, R. W.; Thrasher, J. S. A Convenient an Efficient Method for Incorporation of Pentafluorosulfanyl $\left(\mathrm{SF}_{5}\right)$ Substituents Into Aliphatic Compounds. J. Fluorine Chem. 2006, 127, 1302-1310.

(27) Niina, K.; Tanagawa, K.; Sumii, Y.; Saito, N.; Shibata, N. Pyridine Tetrafluoro- $\lambda^{6}$-Sulfanyl Chlorides: Spontaneous Addition to Alkynes and Alkenes in the Presence or Absence of Photo-Irradiation. Org. Chem. Front. 2020, 7, 1276-1282.

(28) Das, P.; Takada, M.; Tokunaga, E.; Saito, N.; Shibata, N. Synthesis of Pyridine Trans-Tetrafluoro- $\lambda^{6}$-Sulfane Derivatives via Radical Addition. Org. Chem. Front. 2018, 5, 719-724.

(29) Pitts, C. R.; Santschi, N.; Togni, A. WO Patent Appl. 2019229103, 2019.

(30) Shou, J. Y.; Xu, X. H.; Qing, F. L. Chemoselective Hydro(Chloro)pentafluorosulfanylation of Diazo Compounds with Pentafluorosulfanyl Chloride. Angew. Chem., Int. Ed. 2021, 60, $15271-15275$.

(31) Rombach, D.; Wagenknecht, H. A. Photoredox Catalytic Activation of Sulfur Hexafluoride for Pentafluorosulfanylation of $\alpha$ Methyl- and $\alpha$-Phenyl Styrene. ChemCatChem 2018, 10, 2955-2961.

(32) Rombach, D.; Wagenknecht, H.-A. Photoredox Catalytic $\alpha$ Alkoxypentafluorosulfanylation of $\alpha$-Methyl- and $\alpha$-Phenylstyrene Using $\mathrm{SF}_{6}$. Angew. Chem., Int. Ed. 2020, 59, 300-303.

(33) Rombach, D.; Birenheide, B.; Wagenknecht, H. A. Photoredox Catalytic Pentafluorosulfanylative Domino Cyclization of alphaSubstituted Alkenes to Oxaheterocycles by Using $\mathrm{SF}_{6}$. Chem. - Eur. J. 2021, 27, 8088-8093.

(34) Chadha, N.; Silakari, O. Indoles as Therapeutics of Interest in Medicinal Chemistry: Bird's Eye View. Eur. J. Med. Chem. 2017, 134, 159-184.

(35) Usachev, B. I. 1-/2-/3-Fluoroalkyl-Substituted Indoles, Promising Medicinally and Biologically Beneficial Compounds: Synthetic Routes, Significance and Potential Applications. J. Fluorine Chem. 2016, 185, 118-167.

(36) Sravanthi, T. V.; Manju, S. L. Indoles - A Promising Scaffold for Drug Development. Eur. J. Pharm. Sci. 2016, 91, 1-10.

(37) Tatsuta, K.; Morisawa, Y. JP Patent Appl. 2004067524, 2004.

(38) Welch, J. T.; Lim, D. Fluorinated Heterocycles; American Chemical Society, 2009; Vol. 1003, pp 165-181.

(39) Pettersson, M. Y.; Johnson, D. S.; Subramanyam, C.; O'donnell, C. J.; Am Ende, C. W.; Green, M. E.; Patel, N. C.; Stiff, C. M.; Tran, T. P.; Kauffman, G. W.; Stepan, A. F.; Verhoest, P. R. WO Patent Appl. 2015049616, 2015.

(40) Alverez, C.; Arkin, M. R.; Bulfer, S. L.; Colombo, R.; Kovaliov, M.; LaPorte, M. G.; Lim, C.; Liang, M.; Moore, W. J.; Neitz, R. J.; Yan, Y.; Yue, Z.; Huryn, D. M.; Wipf, P. Structure-Activity Study of Bioisosteric Trifluoromethyl and Pentafluorosulfanyl Indole Inhibitors of the AAA ATPase p97. ACS Med. Chem. Lett. 2015, 6, 1225-1230.

(41) Huryn, D. M.; Wipf, P.; Laporte, M. G.; Colombo, R.; Kovaliov, M.; Lim, C.; Alverez, C. N.; Yue, Z.; Samahkumara, L. P.; Chatterley, A. J.; Yan, Y.; Liang, M.; Green, N. J.; Moore, W.; Baldwin, E.; Arkin, M. R.; Neitz, J.; Bulfer, S.; Ang, K.-H.; Bryant, C. WO Patent Appl. 2017070320, 2017.

(42) Bardiot, D. A. M.-E.; Bonfanti, J.-F.; Coesemans, E.; Kesteleyn, B. R. R.; Marchand, A. D. M.; Raboisson, P. J.-M. B. WO Patent Appl. 2017167952, 2017.

(43) Iakobson, G.; Pošta, M.; Beier, P. Synthesis of Pentafluorosulfanyl-Containing Indoles and Oxindoles. Synlett 2013, 24, 855859.
(44) Chen, J.; Xu, L.; Mi, X. Palladium-Catalyzed Oxidative Synthesis of $\mathrm{SF}_{5}$-Indoles. Tetrahedron Lett. 2015, 56, 4204-4206.

(45) Frischmuth, A.; Unsinn, A.; Groll, K.; Stadtmüller, H.; Knochel, P. Preparations and Reactions of $\mathrm{SF}_{5}$-Substituted Aryl and Heteroaryl Derivatives via $\mathrm{Mg}$ and $\mathrm{Zn}$ Organometallics. Chem. - Eur. J. 2012, 18, 10234-10238.

(46) Alabugin, I. V.; Gilmore, K.; Manoharan, M. Rules for Anionic and Radical Ring Closure of Alkynes. J. Am. Chem. Soc. 2011, 133, 12608-12623.

(47) Gilmore, K.; Alabugin, I. V. Cyclizations of Alkynes: Revisiting Baldwin's Rules for Ring Closure. Chem. Rev. 2011, 111, 6513-6556.

(48) Gilmore, K.; Mohamed, R. K.; Alabugin, I. V. The Baldwin Rules: Revised and Extended. WIREs Comput. Mol. Sci. 2016, 6, 487514.

(49) Ye, Y.; Cheung, K. P. S.; He, L.; Tsui, G. C. Synthesis of 2(Trifluoromethyl)indoles via Domino Trifluoromethylation/Cyclization of 2-Alkynylanilines. Org. Lett. 2018, 20, 1676-1679.

(50) 2-Ethynylanilines protected with a tosyl group proved to be the best candidate for both $\mathrm{SF}_{5} \mathrm{Cl}$ addition and cyclization step; see Supporting Information for details.

(51) Miura, K.; Ichinose, Y.; Nozaki, K.; Fugami, K.; Oshima, K.; Utimoto, K. Triethylborane-Induced Hydrodehalogenation of Organic Halides by Tin Hydrides. Bull. Chem. Soc. Jpn. 1989, 62, 143-147.

(52) Ollivier, C.; Renaud, P. Organoboranes as a Source of Radicals. Chem. Rev. 2001, 101, 3415-3434.

(53) All X-ray crystal structures are displayed using CYLview20; Legault, C. Y. CYLview Visualization and Analysis Software for Computational Chemistry; www.cylview.org (accessed 2021-06-22).

(54) Gilbert, A.; Paquin, J.-F. Evaluation of the Compatibility of Pentafluorosulfanyl Chloride with Various solvents and Additives. $J$. Fluorine Chem. 2019, 221, 70-74.

(55) See Supporting Information for details.

(56) Control experiments were conducted to confirm that $\mathrm{SF}_{5}$ alkynes 3 and $\mathrm{N}$-Ts-2-SF $\mathrm{SF}_{5}$-indoles $\mathbf{4}$ are synthetic intermediates in the reaction sequence described in Scheme 3: they were independently reacted with $\mathrm{LiOH}$ in DMSO. Complete conversion to a single product, 5 , was obtained in each case.

(57) Hubbard, J. S.; Harris, T. M. Condensations at the 6 Position of the Methyl Ester and the Dimethylamide of 3,5-Dioxohexanoic Acid via 2,4,6-Trianions. J. Org. Chem. 1981, 46, 2566-2570.

(58) Parrick, J.; Yahya, A.; Jin, Y. A Convenient Conversion of Indoles to 3,3-Dibromooxindoles and Then to Isatins. Tetrahedron Lett. 1984, 25, 3099-3100.

(59) Saikia, I.; Borah, A. J.; Phukan, P. Use of Bromine and BromoOrganic Compounds in Organic Synthesis. Chem. Rev. 2016, 116, 6837-7042.

(60) Bocchi, V.; Palla, G. High Yield Selective Bromination and Iodination of Indoles in N,N-Dimethylformamide. Synthesis 1982, 1982, 1096-1097.

(61) Barl, N. M.; Sansiaume-Dagousset, E.; Karaghiosoff, K.; Knochel, P. Full Functionalization of the 7-Azaindole Scaffold by Selective Metalation and Sulfoxide/Magnesium Exchange. Angew. Chem., Int. Ed. 2013, 52, 10093-10096.

(62) Jones, R. M.; Buzard, D. J.; Kawasaki, A. M.; Kim, S. H.; Thoresen, L.; Lehmann, J.; Zhu, X. US Patent Appl. 20110160243, 2011.

(63) Yue, D.; Larock, R. C. Synthesis of 3-Iodoindoles by Electrophilic Cyclization of N,N-Dialkyl-2-(1-alkynyl)anilines. Org. Lett. 2004, 6, 1037-1040.

(64) Crisp, G. T. Variations on a Theme-Recent Developments on the Mechanism of the Heck Reaction and Their Implications for Synthesis. Chem. Soc. Rev. 1998, 27, 427-436.

(65) Joule, J. A. Science of Synthesis Knowledge Updates; Thieme Chemistry, 2010; Vol. 2.

(66) Frurip, D. J.; Elwell, T. Effective Use of Differential Scanning Calorimetry in Reactive Chemicals Hazard Evaluation. Process Saf. Prog. 2007, 26, 51-58. 
(67) Frurip, D. J. Selection of the Proper Calorimetric Test Strategy in Reactive Chemicals Hazard Evaluation. Org. Process Res. Dev. 2008, $12,1287-1292$.

(68) Sheng, M.; Valco, D.; Tucker, C.; Cayo, E.; Lopez, T. Practical Use of Differential Scanning Calorimetry for Thermal Stability Hazard Evaluation. Org. Process Res. Dev. 2019, 23, 2200-2209.

(69) For a recent example from our group about DSC analysis, see: Brach, N.; Le Fouler, V.; Bizet, V.; Lanz, M.; Gallou, F.; Bailly, C.; Hoehn, P.; Parmentier, M.; Blanchard, N. Optimized Synthesis of 7Azaindazole by a Diels-Alder Cascade and Associated Process Safety. Org. Process Res. Dev. 2020, 24, 776-786.

(70) Kütt, A.; Tshepelevitsh, S.; Saame, J.; Lõkov, M.; Kaljurand, I.; Selberg, S.; Leito, I. Strengths of Acids in Acetonitrile. Eur. J. Org. Chem. 2021, 2021, 1407-1419.

(71) Tshepelevitsh, S.; Hernits, K.; Jenčo, J.; Hawkins, J. M.; Muteki, K.; Solich, P.; Leito, I. Systematic Optimization of Liquid-Liquid Extraction for Isolation of Unidentified Components. ACS Omega 2017, 2, 7772-7776.

(72) Tshepelevitsh, S.; Kadam, S. A.; Darnell, A.; Bobacka, J.; Rüütel, A.; Haljasorg, T.; Leito, I. LogP Determination for Highly Lipophilic Hydrogen-Bonding Anion Receptor Molecules. Anal. Chim. Acta 2020, 1132, 123-133.

(73) Young, R. J.; Leeson, P. D. Mapping the Efficiency and Physicochemical Trajectories of Successful Optimizations. J. Med. Chem. 2018, 61, 6421-6467.

(74) Johnson, T. W.; Gallego, R. A.; Edwards, M. P. Lipophilic Efficiency as an Important Metric in Drug Design. J. Med. Chem. 2018, 61, 6401-6420.

(75) Shultz, M. D. Two Decades under the Influence of the Rule of Five and the Changing Properties of Approved Oral Drugs. J. Med. Chem. 2019, 62, 1701-1714.

(76) Böhm, H.-J.; Banner, D.; Bendels, S.; Kansy, M.; Kuhn, B.; Müller, K.; Obst-Sander, U.; Stahl, M. Fluorine in Medicinal Chemistry. ChemBioChem 2004, 5, 637-643.

(77) Huchet, Q. A.; Kuhn, B.; Wagner, B.; Fischer, H.; Kansy, M.; Zimmerli, D.; Carreira, E. M.; Müller, K. On the Polarity of Partially Fluorinated Methyl Groups. J. Fluorine Chem. 2013, 152, 119-128.

(78) Jeffries, B.; Wang, Z.; Troup, R. I.; Goupille, A.; Le Questel, J.Y.; Fallan, C.; Scott, J. S.; Chiarparin, E.; Graton, J.; Linclau, B. Lipophilicity Trends Upon Fluorination of Isopropyl, Cyclopropyl and 3-Oxetanyl groups. Beilstein J. Org. Chem. 2020, 16, 2141-2150.

(79) Jeffries, B.; Wang, Z.; Felstead, H. R.; Le Questel, J.-Y.; Scott, J. S.; Chiarparin, E.; Graton, J.; Linclau, B. Systematic Investigation of Lipophilicity Modulation by Aliphatic Fluorination Motifs. J. Med. Chem. 2020, 63, 1002-1031.

(80) Liu, K.; Kokubo, H. Uncovering Abnormal Changes in $\log P$ After Fluorination Using Molecular Dynamics Simulations. J. Comput.-Aided Mol. Des. 2019, 33, 345-356.

(81) Curvall, M.; Florin, I.; Jansson, T. Mutagenicity of Some Indoles and Related Compounds in the Ames Test. Toxicology 1982, 23, $1-10$.

(82) Zeiger, E. The Test That Changed the World: The Ames Test and the Regulation of Chemicals. Mutat. Res., Genet. Toxicol. Environ. Mutagen. 2019, 841, 43-48. 